\title{
'TRAP-ped with an Acardius': Case Series of Twin Reversed Arterial Perfusion (TRAP) Sequence and Review of Literature
}

\author{
Philipp Quaas $^{1}$ (1) $\cdot$ Filiz Markfeld-Erol ${ }^{2}$
}

Received: 31 August 2020/Accepted: 21 December 2020/Published online: 8 February 2021

(c) The Author(s) 2021

\begin{abstract}
Twin reversed arterial perfusion (TRAP) sequence is a rare but severe condition that affects monochorionic (MC) multifetal pregnancies. In twin pregnancies, it is characterized by a normally developed twin and another twin with missing heart function (acardiac twin or TRAP twin). A variety of risks and complications may affect the normal twin. Management of such pregnancies can be either expectant or interventional. We report four cases of TRAP sequence treated in our institutions and supply an overview on currently existing literature. This case series demonstrates the heterogeneity in manifestations and clinical course of patients affected by this condition. Furthermore, it includes an acardius amorphous of considerable size delivered at 35.6 weeks of gestation.
\end{abstract}

Keywords Monochorionic (MC) pregnancies · Twin reversed arterial perfusion (TRAP) sequence $\cdot$ Acardiac twin · Fetoscopic laser surgery (FLS) · Case series

\section{Introduction}

Twin reversed arterial perfusion (TRAP) sequence is a rare but severe condition that affects monochorionic (MC) multiple pregnancies. In twin pregnancies, it is characterized by a twin with an apparently normal development and

Philipp Quaas

philipp_quaas@hotmail.com; philipp.quaas@usb.ch

1 Department of Obstetrics and Gynecology, University Hospital, University of Basel, Basel, Switzerland

2 Department of Obstetrics and Gynecology, University Hospital, University of Freiburg, Freiburg, Germany one with missing heart function (acardiac twin or TRAP twin) $[1,2]$.

It has been estimated that 1 in 35,000 pregnancies (approximately $1 \%$ of MC pregnancies) is affected by TRAP $[1,3]$. However, recent studies suggest that the incidence may be as high as 1 in 9,500-11,000 pregnancies (approx. $2.6 \%$ of MC pregnancies) [4]. This higher estimate is attributed to increased detection rate and expanding use of assisted reproductive technologies (ART) [3, 5]. Although most cases in literature describe twin pregnancies there are reports of TRAP sequence in triplet gestations $[6,7]$.

The acardiac twin is reversely perfused through an arterioarterial anastomosis by the normal or "pump" twin. Superior body parts of the TRAP twin often develop rudimentarily due to an insufficient perfusion with deoxygenated blood [7]. The term "Acardius" refers to partial or complete absence of the heart (2). There are four different types of acardiac twins: acardius anceps (head only partially developed), acardius acephalus (headless), acardius acormus (head without body trunk), and acardius amorphous (shapeless mass) $[8,9]$.

The pump twin perfuses the acardiac twin and receives further deoxygenated blood back from it $[10,11]$. The pump twin thus has a significantly higher cardiac workload. Given that fact, the acardiac twin is also known as parasitic twin $[2,8]$.

Potential complications for the pump twin include aspects related to congestive heart failure e.g. hydramnios, hydrops, preterm delivery, intrauterine or postnatal death $[1,2,4,12]$. Mortality rates for the pump twin are estimated to be at least $50 \%$ if TRAP is left untreated [1,3].

Management of TRAP pregnancies may be expectant or interventional. Radiofrequency ablation (RFA) is the predominantly used intervention in this setting $[3,13]$. In RFA the base of the umbilical cord of the acardiac twin is 
thermocoagulated through deployment of tines in the surrounding abdominal wall [13]. Alternative approaches include fetoscopic laser surgery (FLS), ablation with alcohol or microwaves, electrosurgical coagulation of the cord and focused high-frequency ultrasound [3, 4, 14].

In this case series, we describe the clinical course and management of four pregnancies affected by the TRAP sequence in our institutions.

\section{Cases}

\section{Case 1}

A 39-year-old woman was admitted at 23.3 weeks gestation because of preterm labor. Respiratory distress syndrome (RDS) prophylaxis had already been initiated. The patient's medical history was significant for an enlarged fibroid uterus and two recent first trimester miscarriages following ART. After intracytoplasmic sperm injection (ICSI) the patient conceived monochorionic diamniotic (MCDA) twins that demonstrated distinct signs of TRAP sequence on first trimester screening. The patient decided for expectant management. At 21.0 weeks gestation the pump twin was affected by severe fetal growth restriction (FGR), with steady growth of the acardiac mass. There was no referral to a perinatal center. When admitted to our hospital at 23.3 weeks gestation, the patient presented with strong and regular contractions as well as a cervical shortening to $9 \mathrm{~mm}$ with funneling. Following patient consent, intravenous tocolytics were administered according to hospital protocols. Contractions subsided allowing RDS prophylaxis to be completed. The estimated fetal weight was slightly above the fifth percentile. Doppler ultrasound showed borderline pathologic but stable findings throughout hospitalization. At 24.7 weeks gestation the patient experienced strong contractions again, consistent with acute unstoppable preterm labor. A decision was made to proceed with cesarean section. The male pump twin was delivered with a birth weight of $510 \mathrm{~g}$ showing an APGAR score of 3/8/7 and a $\mathrm{pH}$ of 7.38 with a base excess (BE) of - 1.6. Despite immediate transfer to the neonatal intensive care unit (NICU), neonatal demise occurred $50 \mathrm{~h}$ later. The birth weight of the male acardiac twin was $1200 \mathrm{~g}$ [Fig. 1].

\section{Case 2}

A 30-year-old Gravida 2, Para 1 with spontaneously conceived MCDA twins was diagnosed with TRAP sequence at 13.6 weeks of gestation. The acardiac twin showed definitive retrograde perfusion. It had a missing cranium as well as the upper extremities, while the chest and lumbar spine as well as the lower extremities were developed completely. Intervention with FLS was discussed with the patient. The pregnancy was monitored through weekly ultrasound controls. Since spontaneous relative regression of the acardiac mass was observed in the ongoing pregnancy, no intervention was performed, and the patient was managed expectantly until the third trimester. The pump twin was increasingly affected by FGR and oligohydramnios while the cerebroplacental ratio (CPR) was steadily decreasing. At 35.0 weeks of gestation the patient underwent an uneventful Oxytocin challenge test (OCT), and labor was induced with intracervical prostaglandin gel. At 35.3 weeks gestation the patient had an uncomplicated vaginal delivery. The birth weight was $2200 \mathrm{~g}$, with APGAR scores of 9/10/10 and a pH of 7.34. There were no signs of congestive heart failure upon transfer to the NICU for observation. The healthy child was returned to the mother on post-delivery day one. The degenerated parasitic twin showed a weight of $86 \mathrm{~g}$.

\section{Case 3}

A 35-year-old multiparous woman was referred for her fetal anatomy scan at 20.3 weeks gestation. Her referral information mentioned a spontaneously conceived twin pregnancy with missed abortion of one twin at around 7 weeks gestation. On ultrasound, a MC twin pregnancy with a TRAP sequence was diagnosed. Development of the pump twin was appropriate for gestational age while the acardiac twin displayed signs of hydrops and was missing all body parts except the abdomen and lower extremities. The patient was referred to another tertiary referral center (Department of Obstetrics and Fetal Medicine at the University Hospital Hamburg-Eppendorf in Hamburg, Germany) where she underwent FLS at 22.1 weeks of gestation with no complications. Follow-up visits at 24.3 weeks gestation and thereafter revealed regression of the parasitic twin. The pump twin developed oligohydramnios during the course of the pregnancy. Following close surveillance through weekly ultrasound and/or cardiotocographic (CTG) controls including management of a newly diagnosed gestational diabetes, a healthy girl was delivered via cesarean section at 38.2 weeks gestation with a birth weight of $2660 \mathrm{~g}$, APGAR scores of 9/10/10 and a $\mathrm{pH}$ of 7.34. The Acardius was delivered together with the placenta [Figs. 2 and 3].

\section{Case 4}

A 24-year-old woman presented in first trimester with a naturally conceived MCDA twin pregnancy with newly diagnosed TRAP sequence. There were no signs of cephalic or thoracic structures in the acardiac mass, and 
Fig. 1 Acardius anceps from case 1 delivered at 24.7 weeks gestation with a birth weight of 1200 g. The head shows partial development while body and extremities are completely developed
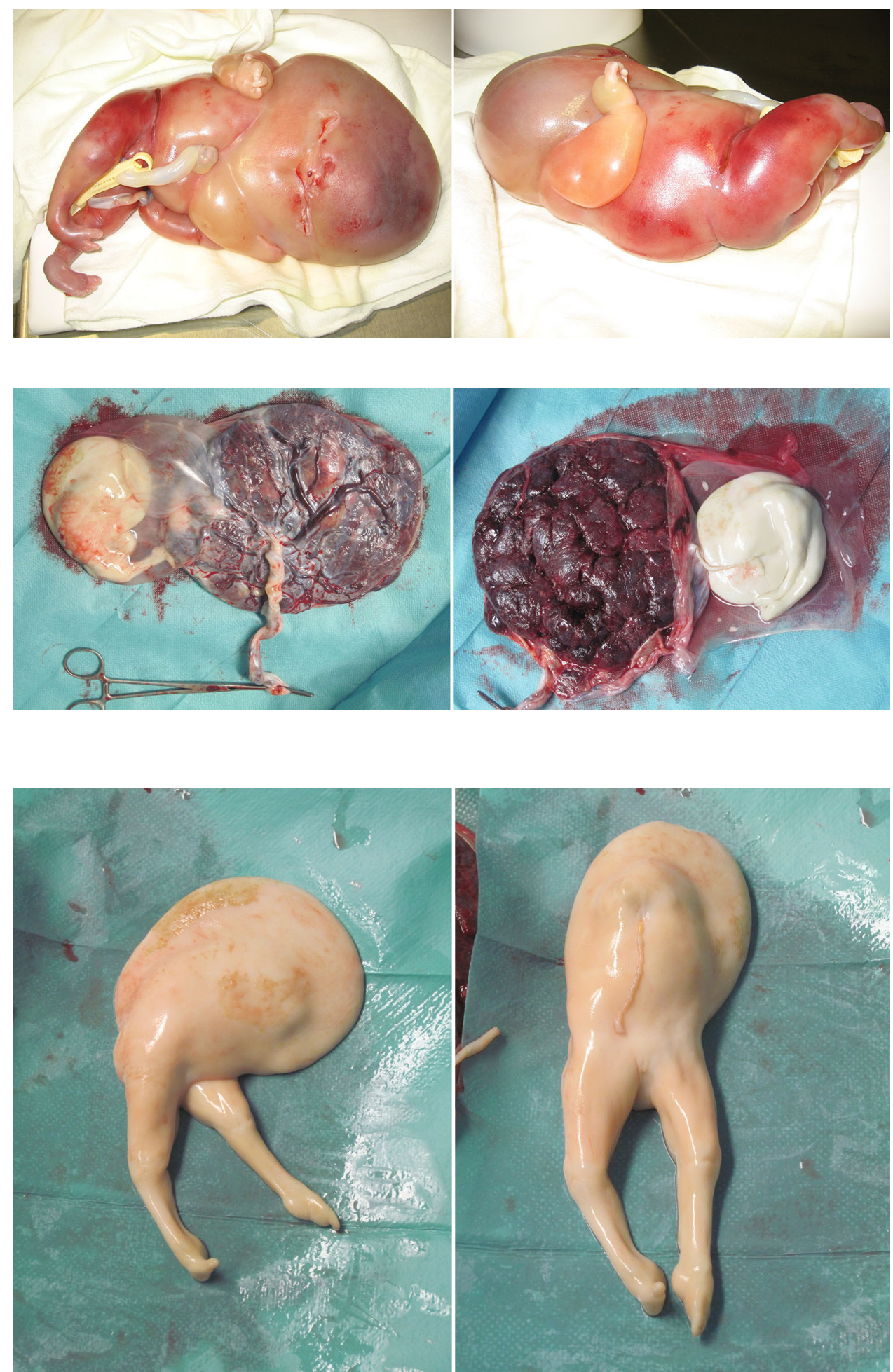

Fig. 3 Acardius acephalus from case 3 without the placenta. The acardiac twin is headless and lacks thoracic organs with no development of upper extremities

Fig. 2 Acardius acephalus from of the monochorionic (MC) delivered at 38.2 weeks gestation. The patient surgery (FLS) at 22.1 weeks of gestation and the acardiac twin Remains of thent regression. be seen on the picture

upper and lower extremities were missing. Size of the TRAP twin was comparable to that of the pump twin. Options of possible interventions were reviewed but the couple decided to pursue expectant management. The pregnancy was closely monitored at regular intervals.
Hemodynamic stability of the pump twin and steady growth of the acardiac twin was observed [Fig. 4]. After completion of RDS prophylaxis, the twins were delivered via cesarean section at 35.6 weeks of gestation. Birth weight of the pump twin was $2765 \mathrm{~g}$ with APGAR scores 

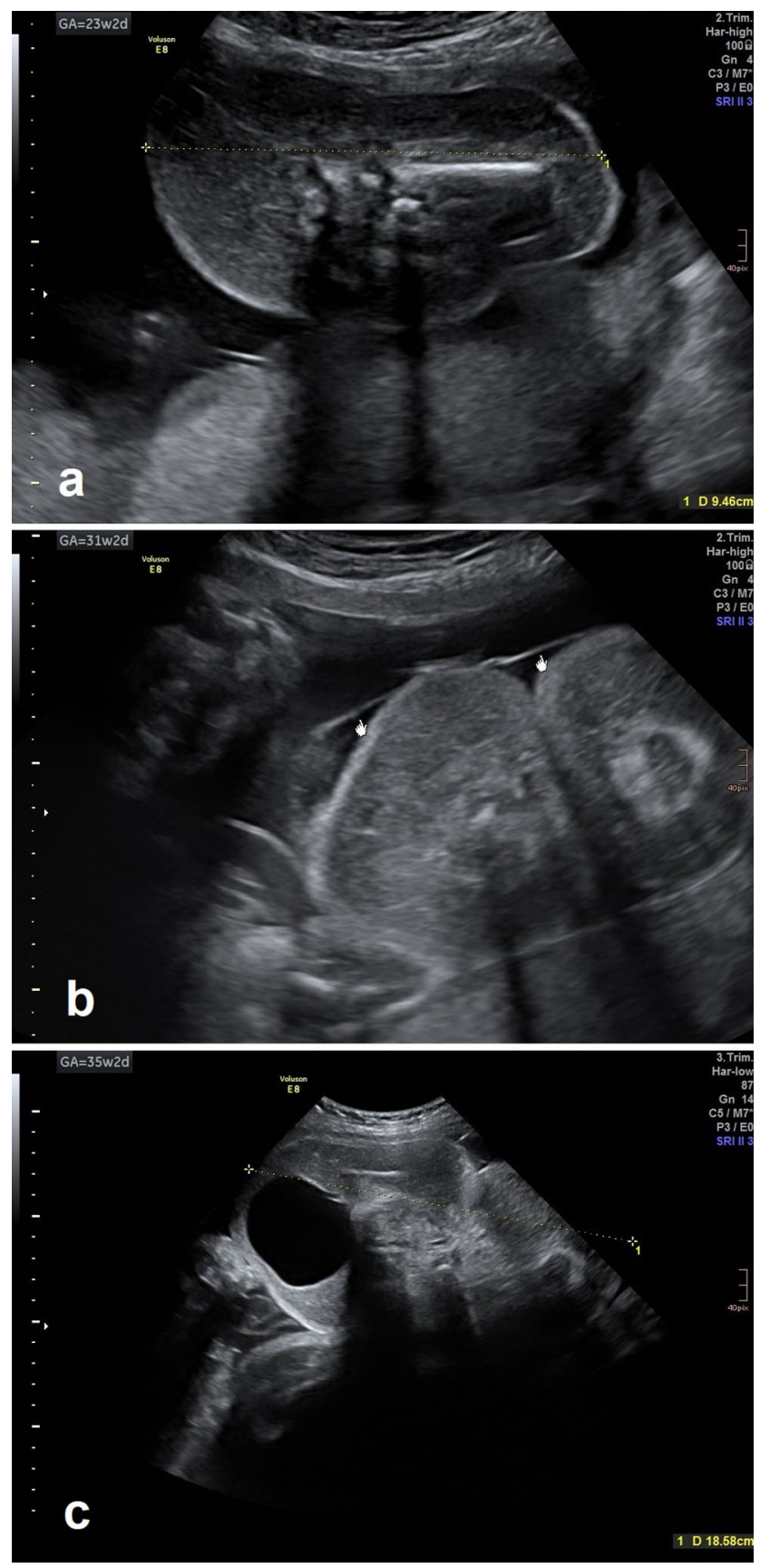

Fig. 4 Ultrasound pictures of the acardius amorphous from case 4 at 23.2 weeks gestation (a), 31.2 weeks gestation (b) and 35.2 weeks gestation (c). The arcadiac twin shows steady growth as well as oligohydramnios. There are sonographic signs of bone and muscle tissue

of 10/10/10 and a $\mathrm{pH}$ of 7.36. The skin color and body temperature of the Acardius with a birth weight of $1340 \mathrm{~g}$ was normal, but there was no visible movement [Figs. 5 and 6]. Following a normal neonatal evaluation, the healthy twin was directly returned to the mother.

\section{Discussion}

\section{Case discussion}

Case 1 (acardius anceps) describes a patient with a highrisk history and pregnancy who should be subjected to close monitoring and care through an experienced obstetrical specialist in the first place. Despite diagnosis of TRAP sequence in early pregnancy with subsequently developing FGR of the pump twin at 21.0 weeks gestation, referral to a perinatologist was not initiated until complications occurred. RDS prophylaxis was administered despite the poor prognosis for this highly desired pregnancy. The patient was subjected to a considerable amount of psychological strain. This case unfortunately demonstrates an example of poor management of a pregnancy affected by TRAP sequence.

The patient described in case 2 (acardius acephalus) was diagnosed with the correct condition around the time of first trimester screening, with consequent and prompt referral to a specialist, allowing adequate counseling and informed decision-making regarding expectant versus interventional management. In the context of retrograde perfusion and discordant growth of the twins, the patient chose to proceed with expectant management which assumably might be the preferable option in this specific situation. [3, 15] Close ultrasound monitoring revealed development of FGR and oligohydramnios in later stages of the pregnancy. Increasingly abnormal results from Doppler ultrasound resulted in active obstetrical management. The patient was subjected to an OCT in order to examine the capacity of the pump twin to withstand contractions after labor induction. It is important to mention here, that an OCT is not part of the standard of care. Following labor induction, vaginal delivery of a healthy child was achieved. Obstetrical management in this case may be regarded as adequate.

The patient in case 3 (acardius acephalus) was initially misdiagnosed with missed abortion of the TRAP twin, likely due to a lack of awareness of TRAP sequence and appropriate ultrasound monitoring in the setting of MC twin pregnancies. Diagnosis and referral unfortunately occurred later in pregnancy, resulting in late intervention via FLS. The risk of complications from FLS increases with gestational age related to the increasing size of the Acardius. [3, 4, 15, 16] In this case, despite the poor prognosis through suboptimal management, the patient had a successful live birth following regular normal CTG and ultrasound (Doppler) monitoring.

The patient described in case 4 (acardius amorphous) was diagnosed and referred in early pregnancy. The couple was counseled regarding early intervention due to 
Fig. 5 Acardius amorphous from case 4 delivered via cesarean section at 35.6 weeks of gestation inside and outside the amniotic sac. The acardiac twin is a rather shapeless mass with rudimentarily developed foot. Parts of the small intestine can be seen on the picture
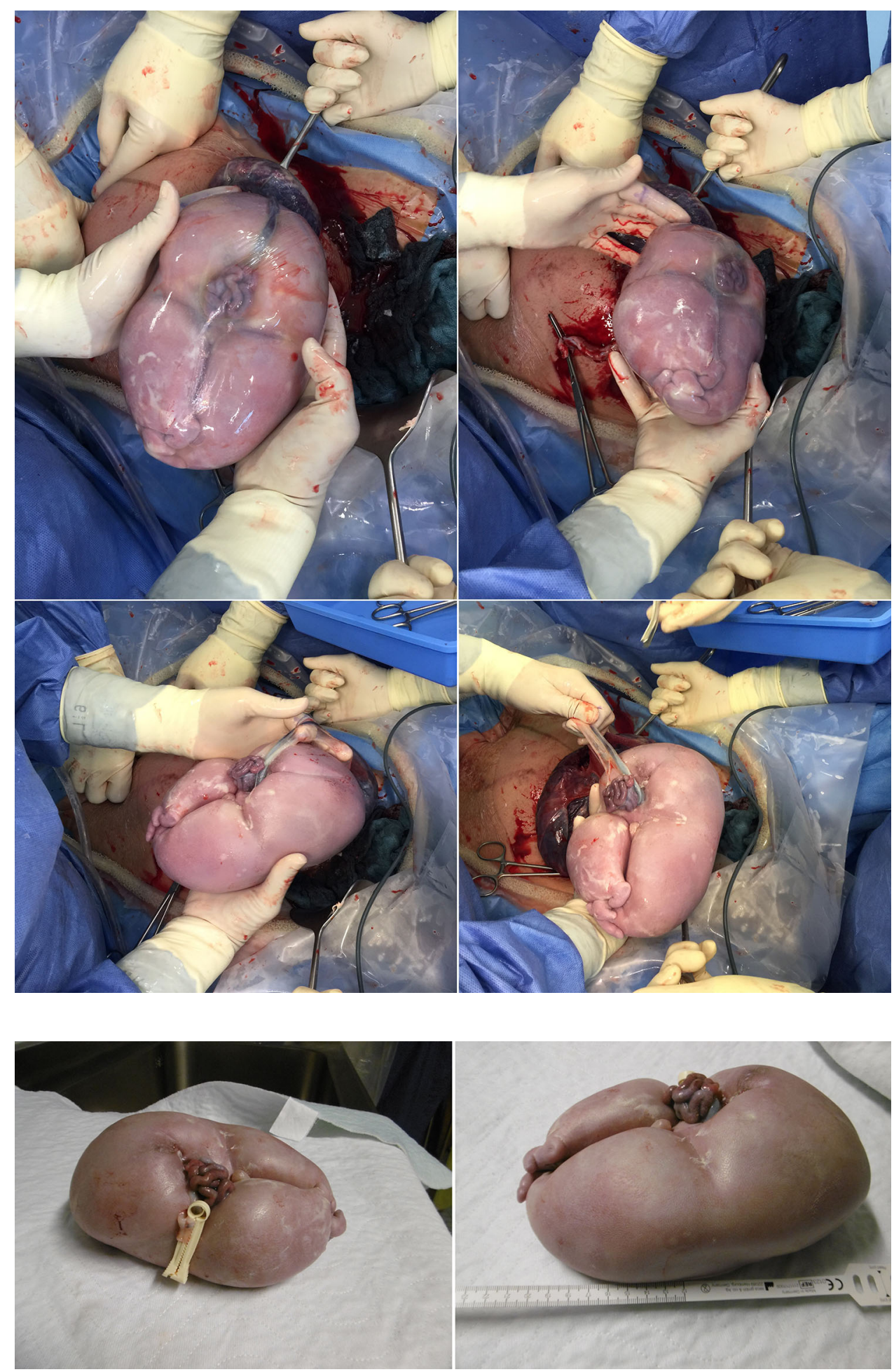

Fig. 6 Acardius amorphous from case 4 after the cesarean section showing a birth weight of $1340 \mathrm{~g}$ and a size of approximately $21 \mathrm{~cm}$ comparable growth of the acardiac and pump twin, and the associated known poor prognosis. [16] Despite the fact that the couple declined intervention, a positive outcome was observed, with live birth of the pump twin via cesarean section at 35.6 weeks following RDS prophylaxis. The couple declined autopsy and karyotypic analysis of the acardiac twin. In this case series, only the Arcadius of case 1 received an autopsy. 


\section{General discussion}

This case series illustrates the diverse variability of the clinical manifestations in patients with $\mathrm{MC}$ multiple pregnancies affected by the TRAP sequence. [8] It also illustrates the variety of different TRAP phenotypes encountered, making them even harder to recognize in the context of an already rare condition. It emphasizes the difficulty in early diagnosis due to a lack of awareness of the TRAP sequence among obstetricians and gynecologists, and lack of ultrasound monitoring in the setting of a MC twin pregnancy, emphasizing the need for close monitoring and early specialist referral. The phenotypic variability also complicates management and prognosis of TRAP pregnancies. Although expectant management is an option, it is currently understood that all patients affected by this condition should be offered fetal intervention and that early intervention in the first trimester appears to have better results than later intervention. [16, 17].

Based on our experience, the following recommendations may improve detection and management of pregnancies affected by the TRAP sequence: First, increased awareness of the existence and rising incidence of this entity among general obstetricians and gynecologists. Second, recognition of MC multiple pregnancies as high risk with early referral to a perinatal specialist. Third, consistent management of TRAP pregnancies according to established unified classification systems with the option of fetal intervention in early pregnancy. [3, 15, 16] Fourth, further research to establish reliable parameters that support decision making in pregnancies affected by TRAP sequence such as the TRAPIST trial where results are awaited. [17, 18].

\section{Conclusion}

MC multiple pregnancies affected by the TRAP sequence represent a diverse entity with a low but rising incidence. This case series demonstrates the heterogeneity in manifestations and clinical course of patients affected by this condition. Early detection is crucial to enable optimal management of these pregnancies. Early referral to a specialist at a perinatal center is essential in order to provide adequate counseling and care for patients with this critical diagnosis. Obstetric recommendations and decisions should be individualized based on the specific clinical circumstances, but ideally based on a unified classification system for decision-making. Further research is needed to continuously improve reliable parameters to support decision making in pregnancies affected by the TRAP sequence.
Funding Open Access funding provided by University of Basel.

\section{Compliance with ethical standards}

Availability of data and material The authors confirm that the data supporting the findings of this study are available within the article [and/or] its supplementary materials. The data that support the findings of this study are available from the corresponding author upon reasonable request.

Conflicts of interest The authors declare that they have no conflict of interest.

Consent to participate Informed consent was obtained from all individual participants included in the study.

Ethics approval Ethical approval was waived by the local Ethics Committee of University Freiburg in view of the retrospective nature of the study and all the procedures being performed were part of the routine care.

Human and animal rights The authors affirm that human research participants provided informed consent for publication of the images in Figure(s) 1-6. The participants have consented to the submission of the case series to the journal.

Open Access This article is licensed under a Creative Commons Attribution 4.0 International License, which permits use, sharing, adaptation, distribution and reproduction in any medium or format, as long as you give appropriate credit to the original author(s) and the source, provide a link to the Creative Commons licence, and indicate if changes were made. The images or other third party material in this article are included in the article's Creative Commons licence, unless indicated otherwise in a credit line to the material. If material is not included in the article's Creative Commons licence and your intended use is not permitted by statutory regulation or exceeds the permitted use, you will need to obtain permission directly from the copyright holder. To view a copy of this licence, visit http://creativecommons. org/licenses/by/4.0/.

\section{References}

1. Moore TR, Gale S, Benirschke K. Perinatal outcome of forty-nine pregnancies complicated by acardiac twinning. Am J Obstet Gynecol. 1990;163(3):907-12.

2. Diehl W, Hecher K. Selective cord coagulation in acardiac twins. Semin Fetal Neonatal Med [Internet]. 2007 Dec 1 [cited 2020 Apr 8];12(6):458-63. Available from: https://www.sciencedirect.com/ science/article/pii/S1744165X07000856

3. Zhang ZT, Yang T, Liu CX, Li N. Treatment of twin reversed arterial perfusion sequence with radiofrequency ablation and expectant management: a single center study in China. Eur J Obstet Gynecol Reprod Biol. 2018;225:9-12.

4. Shettikeri A, Acharya V, V S, Sahana R, Radhakrishnan P. Outcome of Pregnancies Diagnosed with TRAP Sequence Prenatally: a Single-Centre Experience. Fetal Diagn Ther [Internet]. 2020 Apr 1 [cited 2020 Nov 10];47(4):301-6. Available from: https://www.karger.com/Article/FullText/503389

5. van Gemert MJC, van den Wijngaard JPHM, Vandenbussche FPHA. Twin reversed arterial perfusion sequence is more common than generally accepted. Birth Defects Res Part A Clin Mol Teratol. 2015;103(7):641-3. 
6. Yıldırım E. Spontaneous triplet pregnancy and trap sequence, case report. BMC Pregnancy Childbirth. 2019;19(1):328.

7. Pan P, Luo G, Tang L, Rolle J, Qin Y, Zeng Q, et al. Monochorionic-triamniotic triplet pregnancy complicated by twin reversed arterial perfusion sequence: case report and literature review. Am J Perinatol Rep. 2017;07(02):e106-10.

8. Mohanty C, Mishra OP, Singh CP, Das BK, Singla PN. Acardiac anomaly spectrum. Teratology. 2000;62(5):356-9.

9. Napolitani FD, Schreiber I. The acardiac monster: A review of the world literature and presentation of 2 cases. Am J Obstet Gynecol [Internet]. 1960 Sep 1 [cited 2020 Apr 8];80(3):582-9. Available from: https://www.sciencedirect.com/science/article/ abs/pii/S0002937816365206?via\%3Dihub

10. De Groot R, Van Den Wijngaard JPHM, Umur A, Beek JF, Nikkels PGJ, Van Gemert MJC. Modeling acardiac twin pregnancies. Ann N Y Acad Sci. 2007;1101:235-49.

11. Peyvandi S, Feldstein VA, Hirose S, Rand L, Brook MM, MoonGrady AJ. Twin-reversed arterial perfusion sequence associated with decreased fetal cerebral vascular impedance. Ultrasound Obstet Gynecol. 2015;45(4):447-51.

12. Lewi L, Valencia C, Gonzalez E, Deprest J, Nicolaides KH. The outcome of twin reversed arterial perfusion sequence diagnosed in the first trimester. Am J Obstet Gynecol [Internet]. 2010 Sep 1 [cited 2020 Apr 8];203(3):213.e1-213.e4. Available from: https:// www.sciencedirect.com/science/article/pii/S000293781000431X? via\%3Dihub

13. Lee H, Wagner AJ, Sy E, Ball R, Feldstein VA, Goldstein RB, et al. Efficacy of radiofrequency ablation for twin-reversed arterial perfusion sequence. Am J Obstet Gynecol [Internet]. 2007 May 1 [cited 2020 Apr 8];196(5):459.e1-459.e4. Available from:
https://www.sciencedirect.com/science/article/pii/S00029378060 24112?via\%3Dihub

14. Seshadri S, Shinde RR, Ram U. Intrafetal laser for midtrimester TRAP sequence-experience from a single center. Prenat Diagn [Internet]. 2020 Jun 26 [cited 2020 Nov 10];40(7):885-91. Available from: https://onlinelibrary.wiley.com/doi/abs/https:// doi.org/10.1002/pd.5707

15. Wong AE, Sepulveda W. Acardiac anomaly: current issues in prenatal assessment and treatment. Prenatal Diag. 2005;25:796-806.

16. Roethlisberger M, Strizek B, Gottschalk I, Mallmann MR, Geipel A, Gembruch U, et al. First-trimester intervention in twin reversed arterial perfusion sequence: does size matter? Ultrasound Obstet Gynecol. 2017;50(1):40-4.

17. Tavares de Sousa M, Glosemeyer P, Diemert A, Bamberg C, Hecher K. First-trimester intervention in twin reversed arterial perfusion sequence. Ultrasound Obstet Gynecol [Internet]. 2020 Jan 1 [cited 2020 Nov 10];55(1):47-9. Available from: https:// pubmed.ncbi.nlm.nih.gov/31486133/

18. TRAP Intervention STudy: Early Versus Late Intervention for Twin Reversed Arterial Perfusion Sequence (TRAPIST). p. https://clinicaltrials.gov/ct2/show/NCT02621645.

Publisher's Note Springer Nature remains neutral with regard to jurisdictional claims in published maps and institutional affiliations. 